
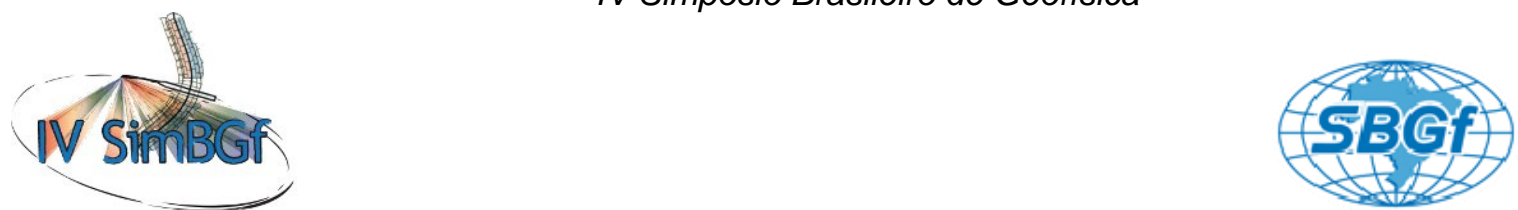

\title{
Construção de unidade de disparo com tempo controlado para experimentos sísmicos
}

Fábio André Perosi, Universidade Federal do Pampa - UNIPAMPA

Celso Bairros Varella Neto*, Universidade Federal do Pampa - UNIPAMPA

Copyright 2010, SBGf - Sociedade Brasileira de Geofísica

Este texto foi preparado para a apresentação no IV Simpósio Brasileiro de Geofísica Brasília, 14 a 17 de novembro de 2010. Seu conteúdo foi revisado pelo Comitê Técnico do IV SimBGf, mas não necessariamente representa a opinião da SBGf ou de seus associados. É proibida a reprodução total ou parcial deste material para propósitos comerciais sem prévia autorização da SBGf.

\begin{abstract}
This project of technological innovation is embedded in the "Geophysical and Tectonic Studies of the Borborema Province and the São Francisco craton, Northeast Brazil" developed by the National Science and Technology Institute of Tectonic Studies, based at the University of Brasília, that will use geophysical tools (modern seismic and seismological methods, gravity, magnetotelluric) and geological to study the structure of the crust and lithosphere in this province. The experiments of Deep Seismic Refraction/Wide Angle Reflection in order to obtain two-dimensional models of that region belong to Borborema project.
\end{abstract}

\section{Introdução}

Nas últimas décadas a visão da crosta e do manto superior foi revolucionada com a exploração sistemática da litosfera continental, principalmente através dos levantamentos de refração e reflexão sísmica profunda e dos métodos sismológicos modernos. Em conseqüência desses levantamentos, feições geológicas maiores puderam ser traçadas até as profundidades da crosta inferior e certas feições da crosta profunda puderam ser projetadas para o manto subjacente. No Brasil estudos deste tipo são escassos, entretanto nos últimos dez anos o interesse da comunidade geocientífica neste tipo de estudo tem aumentado e o conjunto de equipamentos (400 registradores Texans) adquiridos pela Rede de Estudo Tectônicos da Petrobrás facilitará muito futuros projetos desta categoria. Os levantamentos de RSP realizados na Província Tocantins, em 1998, foram pioneiros no país (Perosi, 2000; Berrocal et al., 2004; Perosi, 2006). Naquela ocasião os equipamentos foram emprestados pelo programa PASSCAL (Program for the Array Seismic Studies of Continetal Lithosphere) que é uma das facilidades oferecidas para a comunidade sismológica internacional pelo consórcio norteamericano IRIS (Incorporated Research Institutions for Seismology) que estimula os estudos da litosfera continental e outros estudos sismológicos. Devido a pouca experiência dos brasileiros neste tipo de experimento, o USGS enviou dois técnicos especializados em detonações e a unidade de disparo com controle de tempo portátil, especificamente construída para este fim. Este equipamento permitia a sincronização por GPS, o controle de milésimos de segundo na hora de origem da explosão e automação no procedimento de tiro, reduzindo a possibilidade de erros inseridos por fatores humanos. Em 2008, foi realizada a primeira fase dos estudos de RSP na Província Borborema, que consistia uma linha de aproximadamente $800 \mathrm{~km}$ na direção NOSE, entre os estados de Pernambuco e Ceará. Estes estudos foram financiados pela chamada Institutos do Milênio do CNPq. Nestes levantamentos foram utilizadas espoletas eletrônicas que permitiam o controle da hora de origem, mas não de maneira tão eficiente quanto as unidades de disparo do projeto PASSCAL. Em fevereiro de 2009, em São Paulo, foi realizado um workshop sobre o projeto da Província Borborema para apresentar os dados coletados no final de 2008 e para traçar metas futuras, inclusive para a segunda fase do projeto, agora com recursos do INCT de Estudos Tectônicos. Neste workshop foi instituído um projeto para realizar a construção de unidades de disparo que atendesse as necessidades do projeto e também que pudesse ser utilizada por outros grupos que desejarem utilizar os equipamentos para experimentos de sísmica profunda do Grupo de Estudos Tectônicos da Petrobrás.

\section{Metodologia}

O método de refração sísmica (Sheriff \& Geldart, 1982) se baseia na propagação das ondas elásticas através das camadas do interior da Terra, onde elas são refratadas ou refletidas nas descontinuidades encontradas, seguindo os princípios de Huygens e de Fermat, assim como a lei de Snell, que permitem a reconstrução das trajetórias dos raios sísmicos, desde a fonte até os locais de registro. Utilizando fontes de energia com seus parâmetros conhecidos com muita precisão (localização e hora de origem), é possível inferir essas trajetórias utilizando os tempos de registro dessas ondas, nos diversos registradores distribuídos ao longo da linha sísmica, dos quais se conhece a sua localização. Isto é atingido analisando as curvas caminho-tempo, principalmente das chegadas primárias das ondas registradas. Observa-se que a localização dos pontos e a determinação da hora de origem são parâmetros imprescindíveis para a boa qualidade dos dados e, por conseguinte um bom modelo interpretativo. Assim, a construção de uma unidade de disparo que adequada a estas necessidades é muito importante para otimizar a execução destes projetos. Este equipamento foi dividido em módulos (Figura 1) para facilitar o seu desenvolvimento e montagem. O equipamento é constituído de um microcontrolador, memória eeprom externa, um módulo de interface LCD (display), uma unidade GPS, um circuito de comunicação serial/USB, teclado matricial de programação e uma fonte de alimentação dimensionada para o equipamento.

A fonte de alimentação será desenvolvida baseando-se no consumo do equipamento. A fonte principal será proveniente de uma bateria selada de 12 volts e 7 
Ampères, a qual terá sua tensão reduzida por reguladores de tensão. Todo esse procedimento será automatizado cabendo ao técnico operador simplesmente manter o gatilho apertado nos horários estipulados. Esse é um procedimento de segurança adotado para que o tiro só seja executado na presença de alguma pessoa.

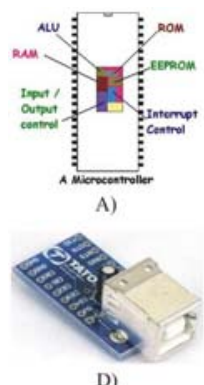

D)

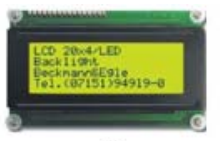

B)

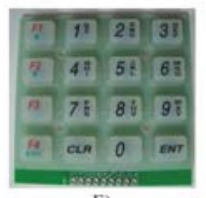

E)

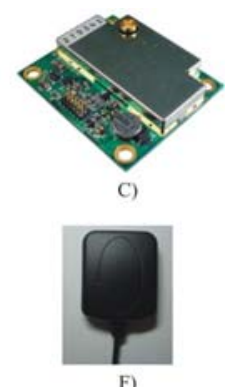

Figura 1 - A) Microcontrolador, B) Display LCD, C) Receptor GPS, D) Serial/USB, E) Teclado Matricial e F) Antena GPS.

\section{Resultados}

Até o presente momento, todo o circuito eletrônico foi montado sob uma protoboard (Figura 2), isto possibilita o desenvolvimento e a alteração de todo o circuito, bem como a reprogramação do firmware da caixa sem a necessidade de utilizar um gravador de microcontrolador externo.

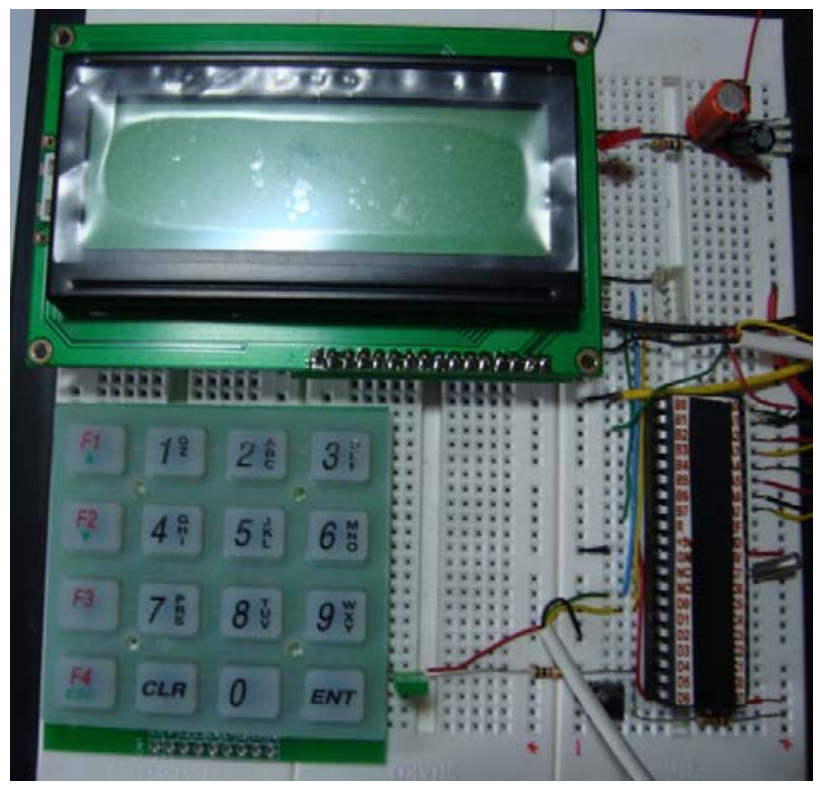

Figura 2 - Protoboard com microcontrolador, display LCD, teclado matricial e fonte de alimentação.

O módulo GPS (Global Position System) tem por finalidade prover o horário UTC (universal time clock) para o microcontrolador, este por sua vez utiliza um cristal de quartzo para incrementar o horário automaticamente sem a necessidade de ficar lendo o GPS, isto é necessário, pois os registradores sísimicos são sincronizados também por GPS.
Tanto o hardware como o firmware foram desenvolvidos para com que a caixa trabalhe em dois modos distintos de operação, controlando o tempo de detonação e como registrador de tempo por pulso externo. No primeiro caso a caixa recebe uma programação de no máximo 50 janelas (horários pré-determinados) de detonação via porta USB e futuramente por teclado, quando este horário se iguala ao do relógio interno da caixa, é enviado um pulso elétrico a um circuito de potência e que por meio de um seletor possibilita ao operador escolher a corrente mais adequada ao tipo de espoleta elétrica utilizada, para maior segurança a caixa é dotada de um gatilho onde só ocorrera a detonação se este estiver acionado por um técnico no horário pré-programado, após a detonação a caixa automaticamente atualiza novamente o seu relógio interno através do GPS, repetindo este processo a cada detonação.

Se por algum motivo a detonação for abortada pelo operador será possível realizar uma nova detonação a partir de dois modos, primeiramente inserindo uma janela de backup para cada um dos horários de detonação pretendidos na programação inicial da caixa, ou através de uma nova programação em campo via teclado sem afetar a seqüência das outras janelas.

Ainda para este modo a caixa disponibiliza uma saída opto-acoplada para ser ligada diretamente ao trigger de sismógrafos, possibilitando a estes iniciar o registro no momento exato da detonação.

O segundo modo de operação consiste em monitorar uma porta conectada a um circuito externo de detonação, na hora em que esta porta receber um pulso a caixa irá armazenar na eeprom externa o horário exato do pulso, possibilitando assim ao operador recuperar estes dados utilizando a porta USB.

Em ambos os modos de operação futuramente será possível armazenar ou somente visualizar a localização dos pontos de tiro (local onde se encontra a caixa) a partir das coordenadas disponibilizadas pelo módulo GPS incluso no circuito.

A partir da verificação em laboratório do funcionamento adequado da caixa, foi dado inicio a faze de confecção da placa de circuito impresso, onde o primeiro passo foi desenhar todo o circuito eletrônico disposto na protoboard codificando-o em simbologia utilizada na eletrônica, assim possibilitando o envio destes dados a empresas especializadas na confecção de tais placas, em posse destas placas começa a faze de montagem e acabamento da caixa. Após esta faze estar completa será dado inicio a faze de testes em campo com a utilização de espoletas elétricas.

\section{Discussão e Conclusões}

Até a presente data foram alcançados vários objetivos importantes tais como: a criação e o desenvolvimento de equipamentos que não existem no Brasil; a participação em projetos multi-institucionais, onde os possíveis resultados podem ser utilizados por outros grupos de pesquisas de universidades brasileiras. Espera-se que essas caixas de tiro possam ajudar na qualidade da aquisição dos dados sísmicos e no processamento dos dados nos próximos levantamentos sísmicos. 


\section{Agradecimentos}

Ao CNPQ (Processo no 482304/2009-0) e ao Professor. Dr. Reinhardt Fuck (UnB) coordenador do INCT de Estudos Tectônicos, por prover suporte financeiro a este projeto. Também, aos funcionários e colegas da Universidade Federal do Pampa - UNIPAMPA por nos auxiliar em várias etapas deste projeto.

\section{Referências}

BERROCAL, J.; MARANGONI, Y.; SÁ, N.C.; FUCK, R.A.; SOARES, J.E.P.; DANTAS, E.L.; PEROSI, F.A.; FERNANDES, C.. Deep seismic refraction and gravity crustal model and tectonic deformation in Tocantins Province, central Brazil. Tectonophysics, 388: 187-199, 2004.

PEROSI, F. A.. Refração Sísmica Profunda no Setor Sudeste da Província Tocantins. Tese (mestrado), IAG/USP, 2000.

PEROSI, F. A.. Estrutura Crustal do Setor Central da Província Tocantins utilizando Ondas $P, S$ e Fases Refletidas com Dados de Refração Sísmica Profunda. Tese (doutorado), IAG/USP, 2006.

SHERIFF, R \& GELDART, L. P.. Exploration Seismology, Cambridge University Press, 2a. Edição,1995. 